\title{
Expression of Dicer in rheumatoid arthritis is associated with disease activity and balances the production of TNF- $\alpha$
}

\author{
SHUJUN WANG ${ }^{1,2}$, MIN YUAN $^{3}$, LIJUN SONG $^{1}$, XIUYING ZHANG ${ }^{2}$, QIN GENG $^{2}$, \\ HONGJU ZHANG ${ }^{2}$ and XINGFU LI ${ }^{1}$ \\ ${ }^{1}$ Department of Rheumatology, Qilu Hospital of Shandong University, Jinan, Shandong 250012; ${ }^{2}$ Department of \\ Rheumatology, Central Hospital of Zibo, Zibo, Shandong 255036; ${ }^{3}$ Department of Rheumatology, \\ People's Hospital of Liaocheng, Liaocheng, Shandong 252002, P.R. China
}

Received May 24, 2016; Accepted April 10, 2017

DOI: $10.3892 / \mathrm{mmr} .2017 .6746$

\begin{abstract}
Gene expression can be altered through RNA interference (RNAi), including microRNA (miRNA) or small interfering RNA. Alterations of miRNAs in rheumatoid arthritis (RA) have been reported, however, the components of the RNAi machinery in RA remain to be fully elucidated. The aim of the present study was to detect the levels of Dicer, Argonaute 2 and Drosha, components of the RNAi machinery, in the peripheral blood mononuclear cells of patients with RAusingreverse transcription-quantitative polymerase chain reaction, and to compare the results with disease activity and clinical features. Disease activity was assessed using the Disease Activity Score 28 (DAS28). Transfection and stimulation of cultured cells were conducted to determine the biological function of Dicer. ELISA was used to test tumor necrosis factor (TNF)- $\alpha$ protein levels. It was found that the mRNA expression levels of Dicer and Drosha were upregulated in patients with RA, and that the increased level of Dicer was correlated with disease activity in patients with RA. Dicer and TNF- $\alpha$ were activated in the serum of patients with RA. The activation of Dicer suppressed the production of TNF- $\alpha$. These results suggested that Dicer can balance the production of TNF- $\alpha$, and thus may serve as a regulator of the immune response in patients with RA.
\end{abstract}

\section{Introduction}

RNA interference (RNAi) is an evolutionarily conserved mechanism for silencing specific genes (1). The process of RNAi can be moderated by either microRNA (miRNA) or

Correspondence to: Professor Xingfu Li, Department of Rheumatology, Qilu Hospital of Shandong University, 107 Wenhua Xi Road, Jinan, Shandong 250012, P.R. China

E-mail: xfuli1@163.com

Key words: rheumatoid arthritis, RNA interference, Dicer, tumor necrosis factor- $\alpha$ small interfering RNA (siRNA). miRNA and siRNA are processed inside the cell by the enzyme, Drosha, Dicerand a complex called RNA-induced silencing complex (RISC) (2-6). The Argonaute (Ago) family of proteins are essential components of RISC, which are involved in mRNA cleavage. Ago2 is the only enzyme conferring this activity in mammals (7). RNAi molecules, which target the degradation of mRNA have the ability to alter cellular pathways and events. RNAi is a useful tool in the treatment of diseases and functional investigations of genes. Furthermore, targeting specific genes using RNAi molecules has been applied in preclinical studies $(8,9)$.

RA is a chronic inflammatory autoimmune disorder, which is high in prevalence and characterized by persistent synovitis and systemic inflammation, often leading to other serious complications. RA can finally lead to joint destruction and functional disability, and patients may succumb to mortality $(10,11)$. However, the pathogenesis of RA remains to be fully elucidated and there are no satisfactory therapeutic strategies to cure this disease $(12,13)$. Alterations of miRNAs in RA have been reported previously. Several aberrantly expressed miRNAs have been found to contribute to various aspects of the pathogenesis of RA and may have applications in biotherapeutic approaches for the diagnosis and treatment of RA (14). For example, miRNA (miR)-24, miR-26a, miR-125a-5p and miR-323-3p are increased in RA, indicating that these miRNAs may be RA biomarkers $(15,16)$. miR-146a is significantly upregulated in RA, and is associated with the level of tumor necrosis factor (TNF)- $\alpha$ and disease activity (17). miR-19 can regulate the expression of Toll-like receptor 2 in rheumatoid fibroblast-like synoviocytes (18). Of note, therapeutic trials aimed at targeting miRNA in arthritis have been performed in vivo models $(19,20)$. Thus, targeting miRNAs offers a novel advanced therapeutic strategy for treating RA.

Alterations of miRNAs in RA have been reported, however, the regulation of these molecules remains to be fully elucidated. The present study investigated whether the mRNA levels of Dicer, Ago2 and Drosha, which are components of the RNAi mechanism, are associated with the clinical signature of RA. Investigations were also performed to investigate the contribution of Dicer, which was identified in our pilot study, to the pathogenesis of RA. 
Table I. Characteristics of the study subjects.

\begin{tabular}{|c|c|c|}
\hline Characteristic & Patients with rheumatoid arthritis $(n=50)$ & Healthy controls $(n=25)$ \\
\hline Female, $n$ & 38 & 19 \\
\hline Male, $\mathrm{n}$ & 12 & 6 \\
\hline Age, years (range) & $55.88(28-85)$ & $56.25(31-78)$ \\
\hline Disease duration, months & 54 & - \\
\hline ILD, n (\%) & $4(8)$ & - \\
\hline Infection, n (\%) & $9(18)$ & - \\
\hline ANA, n $(\%)$ & $22(44)$ & - \\
\hline $\mathrm{RF}, \mathrm{n}(\%)$ & $42(84)$ & - \\
\hline Anti-CCP, n (\%) & $45(90)$ & - \\
\hline $\mathrm{AKA}, \mathrm{n}(\%)$ & $11(22)$ & - \\
\hline DAS28 ${ }^{a}$ & $4.810 \pm 0.2476$ & - \\
\hline Medication & & - \\
\hline Steroids n $(\%)^{\mathrm{b}}$ & $10(20)$ & - \\
\hline$\leq 10 \mathrm{mg} /$ day, $\mathrm{n}(\%)$ & $6(12)$ & - \\
\hline$>10$ mg/day, n (\%) & $4(8)$ & - \\
\hline DMARDs ${ }^{\mathrm{c}}, \mathrm{n}(\%)$ & $49(98)$ & - \\
\hline Anti-TNF agents ${ }^{\mathrm{d}}, \mathrm{n}(\%)$ & $11(22)$ & - \\
\hline
\end{tabular}

${ }^{a}$ Score presented as the mean \pm standard error of the mean. ${ }^{b}$ Dose of steroids were the same as as that of prednisone. If another equivalent

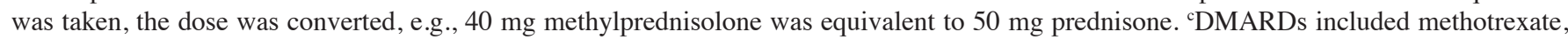
chloroquine, leflunomide, sulfasalazineand iguratimod. ${ }^{\mathrm{d} A n t i-T N F}$ agents included etanercept, infliximab and adalimumab. ILD, interstitial lung disease; ANA, antinuclear antibody; RF, rheumatoid factor; CCP, cyclic citrullinatedpeptide; DMARDs, disease modifying antirheumatic drugs; TNF, tumor necrosis factor.

\section{Materials and methods}

Subjects. A total of 50 patients with RA and 25 healthy controls were recruited following the provision of informed consent from February 2014 to July 2014. The procedure was approved by the Medical Ethics Committee of Central Hospital of Zibo in January 2014. All patients with RA fulfilled the American College of Rheumatology classification criteria for RA. An RA Disease Activity Score (DAS28) for each patient was determined at the time of blood sample collection. Additional clinical information is listed in Table I.

Sample handling and RNA processing. Peripheral blood samples were obtained from each subject and collected in tubes containing acid citrate dextrose formula A. Erythrocytes were immediately lysedin lysis buffer for $20 \mathrm{~min}$ at $4^{\circ} \mathrm{C}$ and total RNA was extracted from the leukocytes using TRIzol (Invitrogen; Thermo Fisher Scientific, Inc.). Subsequently, $1 \mu \mathrm{g}$ of RNA was reverse transcribed into cDNA using SuperScript II reverse transcriptase (Invitrogen; Thermo Fisher Scientific, Inc.) and oligo dT primers.

Quantitative polymerase chain reaction ( $q P C R$ ) analysis.To determine the quantity of mRNA, the cDNA was amplified using qPCR analysis with SYBR-Green (SYBR Premix Ex Taq $^{\text {TM }}$ RT-PCR kit; Takara Biotechnology Co., Ltd., Dalian, China), and the expression of ribosomal protein L13A (RPL13A) was determined as the internal control. The SYBR Green assays were performed on a $7900 \mathrm{HT}$ real-time instrument
(Applied Biosystems; Thermo Fisher Scientific, Inc.). Relative expression levels were calculated using the $2^{-\Delta \Delta \mathrm{Cq}}$ method (21). The primers used were as follows: Dicer forward, 5'-AGG AAGAGGCTGACTATGAAG-3' and reverse, 5'-GGTTGA AAAAGGAGAAAGAGA-3'; Ago2 forward, 5'-GTCTCT GAAGGCCAGTTCCA-3' and reverse, 5'-ATACAGGCCTCA CGGATGG-3'; Drosha forward, 5'-CAGCTACGAACGGAG CAGT-3' and reverse, 5'-TTTTTCTTCCTCCCAACGAG-3'; TNF- $\alpha$ forward, 5'-CCCAGGGACCTCTCTCTAATCA-3' and reverse, 5'-GCTACAGGCTTGTCACTCGG-3'; RPL13A forward, 5'-CCTGGAGGAGAAGAGGAAAGAGA-3' and reverse, 5'-TTGAGGACC TCTGTGTATTTGTCA A-3'. RT-qPCR analysis was performed at $95^{\circ} \mathrm{C}$ for $15 \mathrm{sec}$, followed by 40 cycles at $95^{\circ} \mathrm{C}$ for $5 \mathrm{sec}$ and $60^{\circ} \mathrm{C}$ for $30 \mathrm{sec}$, and then at $95^{\circ} \mathrm{C}$ for $15 \mathrm{sec}, 60^{\circ} \mathrm{C}$ for $15 \mathrm{sec}$ and $95^{\circ} \mathrm{C}$ for $15 \mathrm{sec}$. The results were analyzed using SDS software version 2.3 (Applied Biosystems; Thermo Fisher Scientific, Inc.).

Isolation of peripheral blood mononuclear cells (PBMCs). PBMCs were obtained from healthy volunteer donors. The PBMCs were separated from heparinized whole blood using density-gradient centrifugation at $800 \mathrm{x} \mathrm{g}$ for $20 \mathrm{~min}$ at $37^{\circ} \mathrm{C}$ with LymphoprepFicoll-Paque Plus (GE Healthcare Life Sciences, Chalfont, UK).

Cell culture. The HeLa cells were obtained from the American Type Culture Collection (Manassas, VA, USA) and were maintained at $37^{\circ} \mathrm{C}$ in an atmosphere of $5 \% \mathrm{CO}_{2}$ in Dulbecco's modified Eagle's medium (DMEM; Invitrogen; 
Thermo Fisher Scientific, Inc.) containing 10\% FBS (Invitrogen; Thermo Fisher Scientific, Inc.) and $100 \mathrm{U} / \mathrm{ml}$ of penicillin/streptomycin. The purified PBMCs were cultured in RPMI-1640 medium supplemented with 10\% serum from either a healthy control ora patients with RA, $100 \mathrm{U} / \mathrm{ml}$ of penicillin and $100 \mathrm{U} / \mathrm{ml}$ of streptomycin at $37^{\circ} \mathrm{C}$ in an atmosphere of $5 \% \mathrm{CO}_{2}$.

Transfection and stimulation. The HeLa cells were plated at a density of $5 \times 10^{4}$ in culture dishes for $24 \mathrm{~h}$ and then transfected with $100 \mathrm{nM}$ of Dicer small interfering (si)RNA or control siRNA with Lipofectamine 2000 (Invitrogen; Thermo Fisher Scientific, Inc.) according to the manufacturer's protocol. At $48 \mathrm{~h}$ post-transfection, the HeLa cells were stimulated with lipopolysaccharide (LPS; $10 \mu \mathrm{g} / \mathrm{ml}$ ) from Escherichia coli strain K12; InvivoGen, San Diego, CA, USA) for $2 \mathrm{~h}$ at $37^{\circ} \mathrm{C}$ in an atmosphere of $5 \% \mathrm{CO}_{2}$. The siRNA sequences were as follows: Control siRNA sense, 5 '-CAGUACUUUUGUGUA GUACAAdTdT-3' and antisense, 5'-TTGTACTACACAAAA GTACTGdTdT-3'; Dicer siRNA sense, 5'-ACUGCUUGA AGCAGCUCUGGAdTdT-3' and antisense, 5'-UCCAGAGCU GCUUCAAGCAGUdTdT-3'.

Enzyme-linked immunosorbent assay (ELISA). The protein levels of TNF- $\alpha$ secreted into the cell culture supernatantwere quantified using commercially available ELISA kits (XiTang Biological Technology Co., Ltd., Shanghai, China) according to the manufacturer's protocol.

Statistical analysis. Data were analyzed using Prism 4 software, version 5.01 (GraphPad Software, Inc., La Jolla, CA, USA). The nonparametric Mann-Whitney test was used to compare between groups. Spearman's correlation test was used for correlation analysis. $\mathrm{P}<0.05$ (two-tailed) was considered to indicate a statistically significant difference.

\section{Results}

mRNA expression of Dicer Ago2 and Drosha. The demographic and baseline clinical data of the study subjects are summarized in Table I. The present study examined the mRNA expression levels of Dicer, Ago2 and Drosha in samples obtained from 50 patients with RA and 25 healthy controls using RT-qPCR analysis, as described above. There were no significant differences in mean age or gender distribution between the patients with RA and the healthy donors (Table I). As shown in Fig. 1A, the RA group had a higher mRNA level of Dicer, compared with the healthy controls $(12.86 \pm 6.83$, vs. $1.727 \pm 1.713 ; \mathrm{P}<0.0001)$. There was no significant difference in the mRNA expression of Ago2 between the patients with RA and healthy controls $(1.886 \pm 5.944$, vs. $2.549 \pm 3.3889$; $\mathrm{P}=0.7573$; Fig. 1B). The RA group had a higher mRNA level of Drosha, compared with the healthy controls $(17.14 \pm 34.76$, vs. $2.824 \pm 4.037 \mathrm{P}=0.0235$; Fig. 1C).

Clinical associations. The present study performed analysis to determine the correlation between the mRNA levels of Dicer, Ago2 and Droshaand clinical features. As shown in Fig. 2A, a direct positive correlation was observed between the mRNA levels of Dicer and DAS28 scores $(r=0.4893 ; \mathrm{P}=0.003)$.
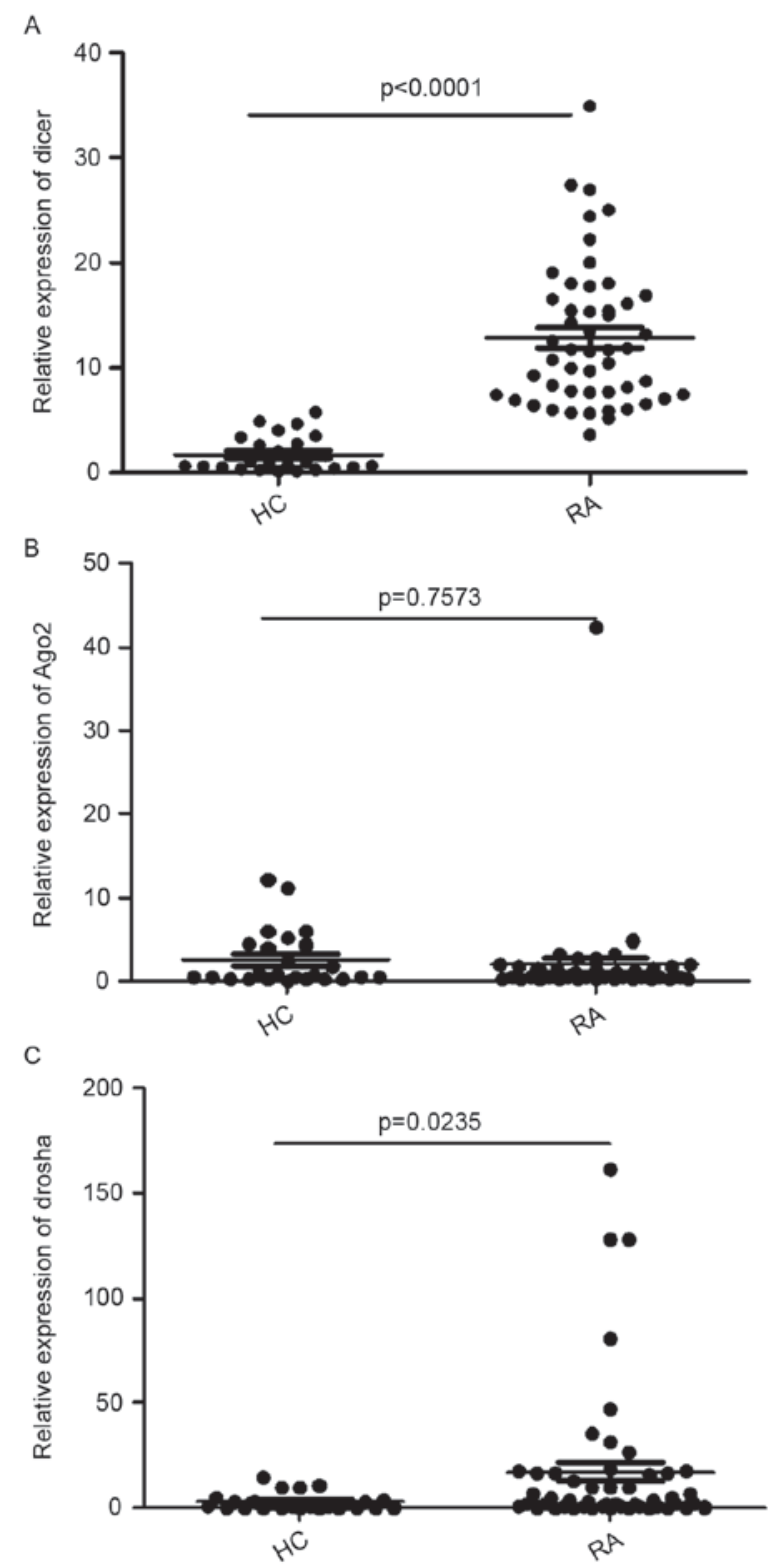

Figure 1. mRNA expression of Dicer Ago2 and Drosha. (A) Comparison of mRNA expression levels of Dicer in patients with RA and healthy controls. (B) Comparison of mRNA expression levels of Ago2 in patients with RA and healthy controls. (C) mRNA expression of Drosha in patients with RA and healthy controls. RA, rheumatoid arthritis; HC, healthy control; Ago2, Argonaute 2.

However, there was no correlation between the mRNA level of Ago2 ( $\mathrm{r}=0.02089 ; \mathrm{P}=0.8855)$ and DAS28 scores or the level of Drosha and DAS28 scores ( $\mathrm{r}=0.08499 ; \mathrm{P}=0.5573)$, as shown in Fig. 2B and C.

The levels of C-reactive protein (CRP) are also an indicator of disease activity. High CRP levels are often observed in patients with RA with active disease. Further analysis in the present study revealed that the mRNA expression levels of Dicer were correlated with the levels of CRP $(r=0.4813$; $\mathrm{P}=0.0004$; Fig. 3A), whereas the mRNA levels of Ago2 $(r=0.1793 ; P=0.2118)$ and Drosha $(r=0.1127 ; P=0.4359)$ were not (Fig. 3B and C). Taken together, these results indicated that the expression levels of Dicer were positively correlate with RA disease activity. 

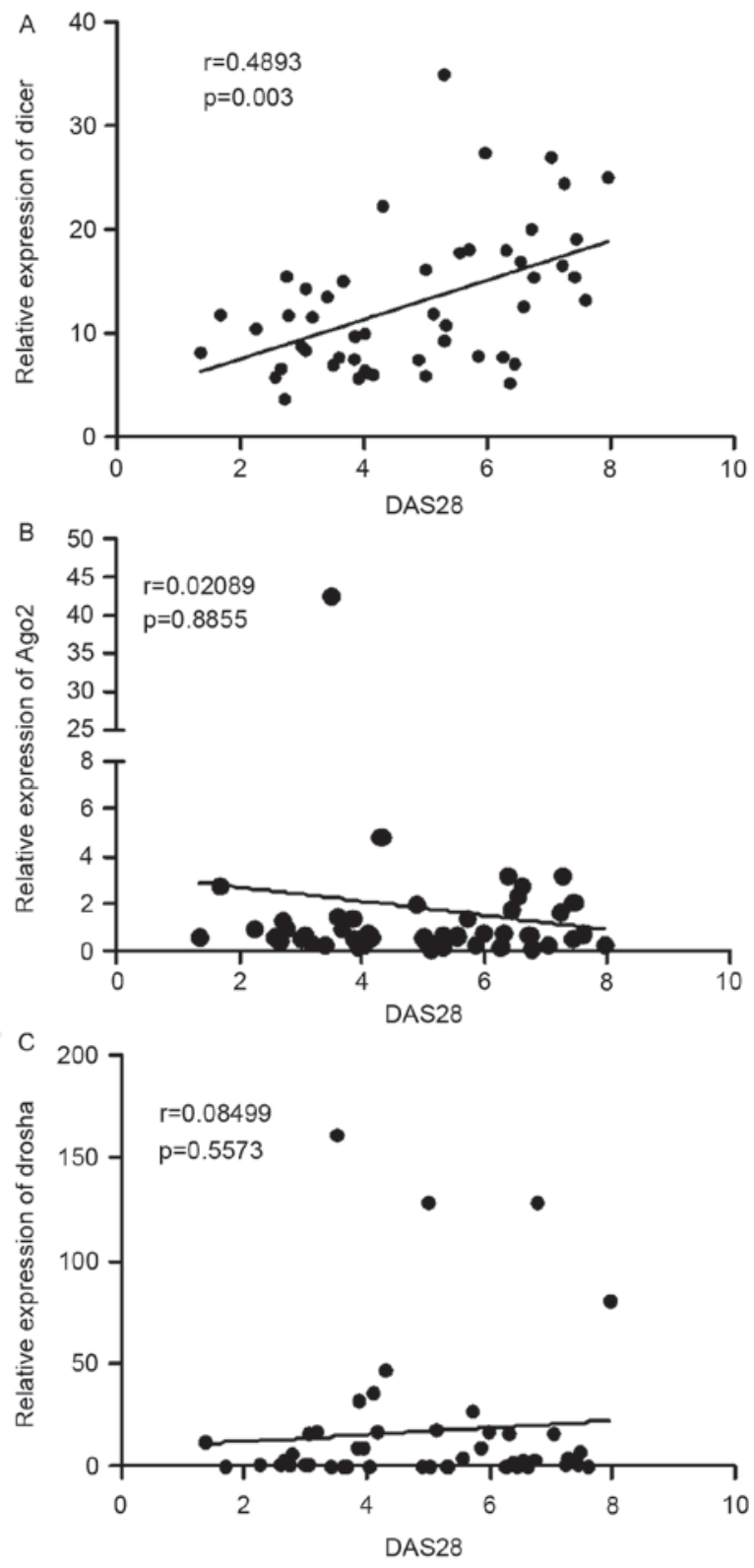

Figure 2. Correlation between the mRNA expression levels of Dicer, Ago2 or Drosha and DAS28 in patients with rheumatoid arthritis. (A) Dicer; (B) Ago2; (C) Drosha. Ago2, Argonaute 2.

Manipulation of Dicer function alters the expression of $T N F-\alpha$. TNF- $\alpha$ is one of the major proinflammatory cytokines involved in the pathogenesis of RA (22). In order to examine the effect of Dicer on TNF- $\alpha$, the present study treated HeLa cells with Dicer siRNA or control siRNA. At $48 \mathrm{~h}$ post-transfection, the HeLa cells were stimulated with LPS $(10 \mu \mathrm{g} / \mathrm{ml})$ for $2 \mathrm{~h}$, following which the protein level of TNF- $\alpha$ was detected using ELISA. Transfection with Dicer siRNA increased the expression of TNF- $\alpha$ (Fig. 4A), suggesting that the expression of TNF- $\alpha$ was regulated by Dicer at the protein level.

The expression of Dicer can be regulated by the let-7/miR-98 family via mRNA degradation and translational repression (23). In the present study, the expression of Dicer was altered by manipulation of miR-98 and the effect on the expression of TNF- $\alpha$ was examined. HeLa cells were treated with miR-98 mimic or inhibitor for $48 \mathrm{~h}$. Following transfection, the HeLa
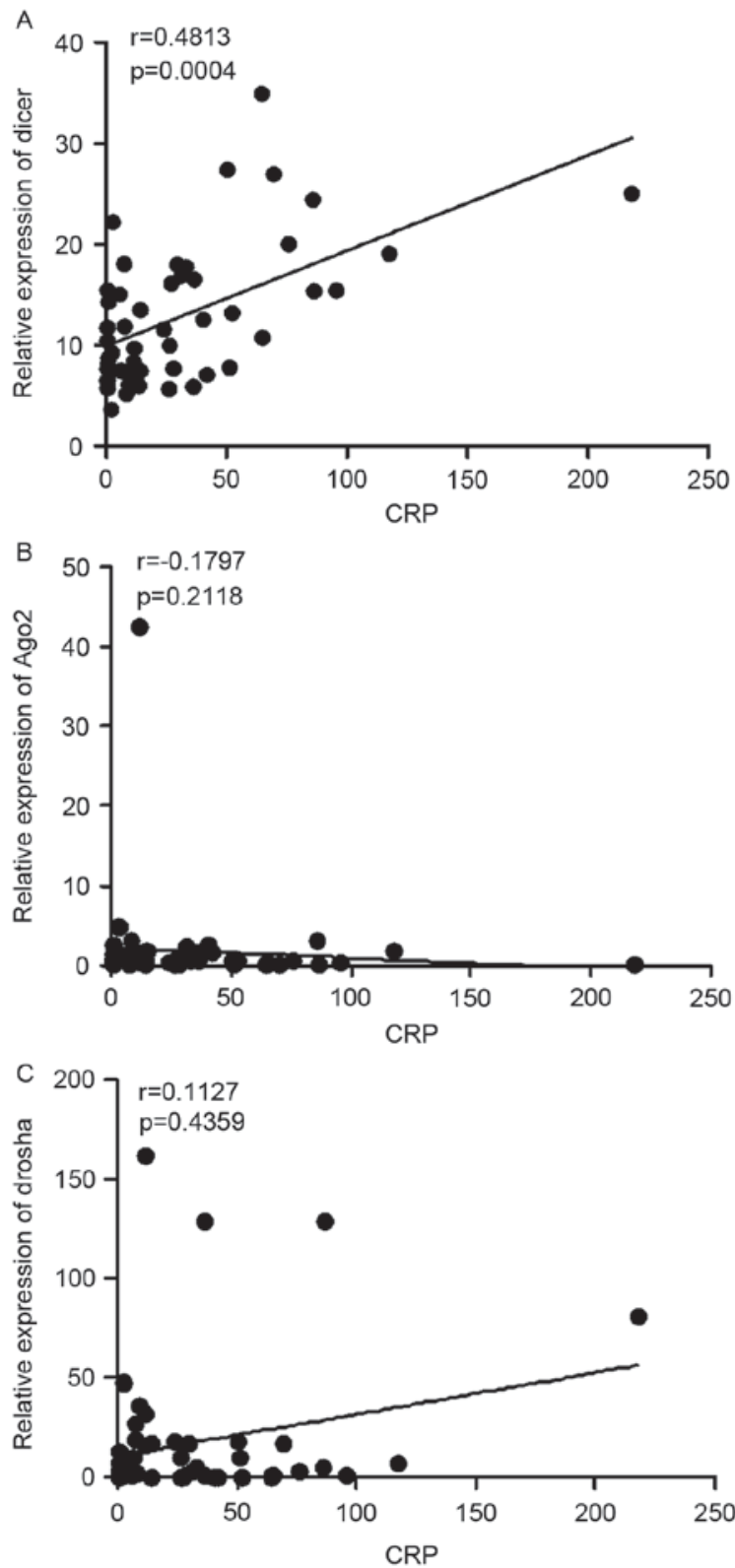

Figure 3. Correlation between the mRNA expression levels of Dicer, Ago2 or Drosha and CRP in all patients with rheumatoid arthritis. (A) Dicer. (B) Ago2. (C) Drosha. CRP, C-reactive protein; Ago2, Argonaute 2.

cells were stimulated with LPS $(10 \mu \mathrm{g} / \mathrm{ml})$ for $2 \mathrm{~h}$ and the protein expression of TNF- $\alpha$ was examined using ELISA. The miR-98 mimic, which downregulated the expression of Dicer, increased the protein expression levels of TNF- $\alpha$, whereas the miR-98 inhibitor, which upregulated the expression of Dicer, decreased theexpression of TNF- $\alpha$ (Fig. 4B), suggesting that the expression of TNF- $\alpha$ was regulated by the manipulation of Dicer.

Expression of Dicer and TNF- $\alpha$ are enhanced following LPS treatment or by supplementation with 10\% serum from patients with $R A$. The excessive stimulation of innate immunity, including LPS, can lead to the overproduction of TNF- $\alpha$ (24). In the present study, PBMCs werefreshly purified from healthy donors and stimulated LPS (10 $\mu \mathrm{g} / \mathrm{ml}$ from $E$. coli strain K12), following which the mRNA levels of TNF- $\alpha$ and Dicer were 


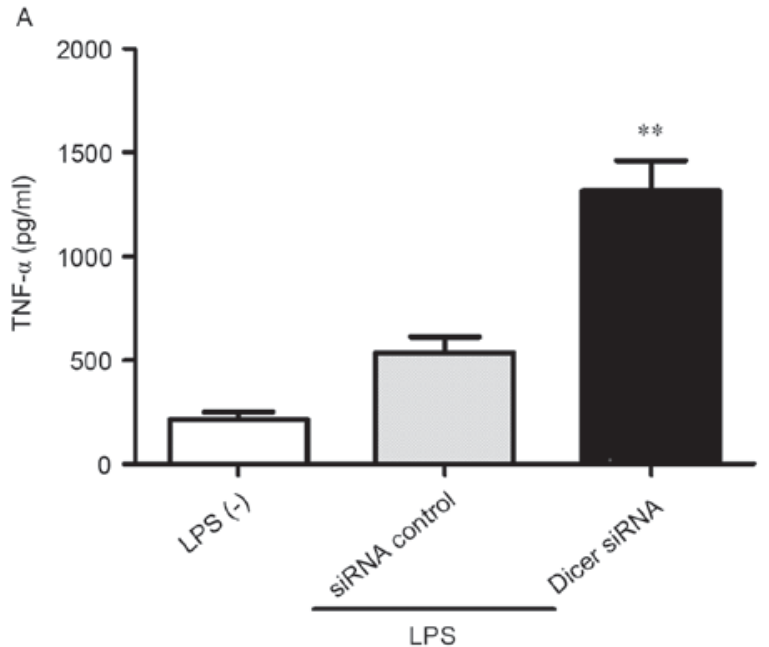

B

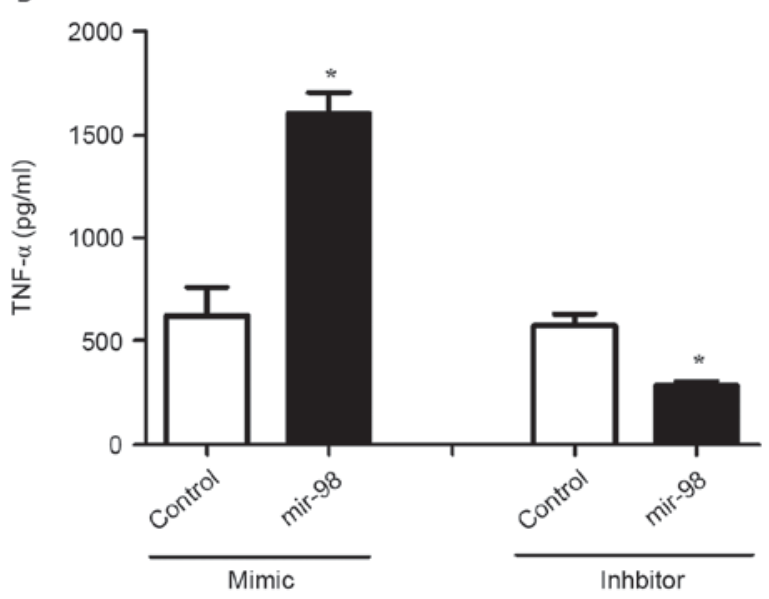

Figure 4. (A) Effects of Dicer siRNA on the protein levels of TNF- $\alpha$ in HeLa cells stimulated by LPS. (B) Effects of miR-98 mimic and inhibitor on the protein levels of TNF- $\alpha$ in HeLa cells stimulated by LPS. Data are presented as the mean \pm standard deviation. ${ }^{*} \mathrm{P}<0.05$ and ${ }^{* *} \mathrm{P}<0.01$, compared with the control. siRNA, small interfering RNA; TNF- $\alpha$, tumor necrosis factor- $\alpha$; LPS, lipopolysaccharide; miR, microRNA.

measured using RT-qPCR analysis at different times post-LPS stimulation. It was found that the mRNA levels of TNF- $\alpha$ and Dicer were enhanced, with a peak $4 \mathrm{~h}$, following LPS treatment (Fig. 5A). This process was mimicked by supplementing the cells with $10 \%$ serum from patients with RA (Fig. 5B).

\section{Discussion}

RNAi, which was initially recognized as an ancient defense strategy protecting organisms from RNA virus infection (25), is an evolutionarily conserved mechanism of post-transcriptional gene silencing in a sequence-specific manner (26). It has been shown that gene silencing by RNAi has emerged as a useful tool for genetic analysis and treatment of disease.

Dicer is important in antiviral responses. It inhibits human immunodeficiency virus type 1 replication in PBMCs (27), and knockdown of Dicer leads to increased virus production and accelerated apoptosis of influenza-A virus-infected cells (28). In vivo, Dicer is essential for normal skeletal growth. Dicer is critical in the regulation of chondrocyte proliferation and differentiation during skeletal development (29). Dicer
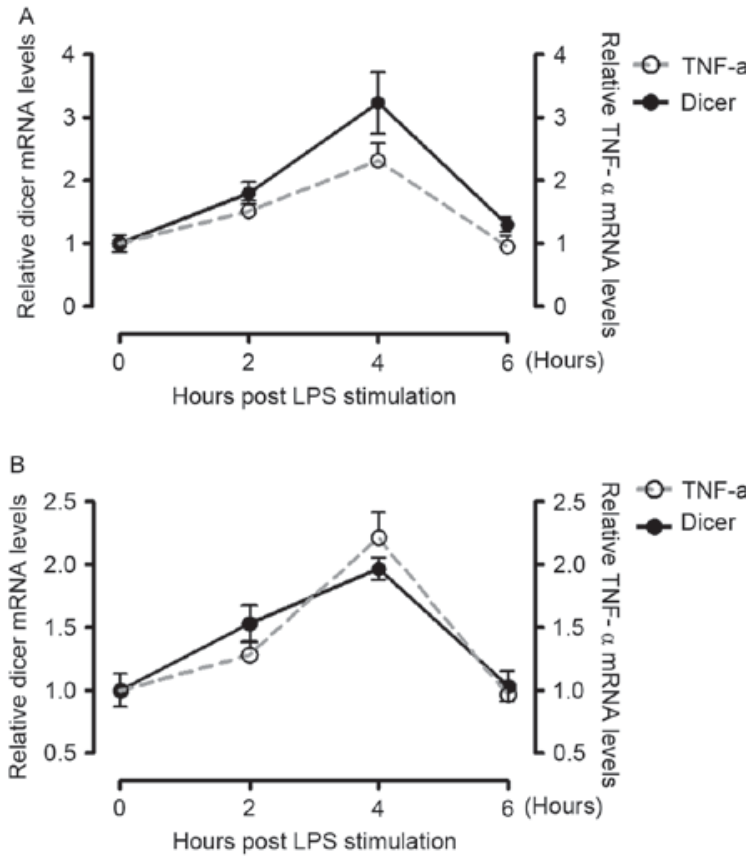

Figure 5. (A) mRNA levels of Dicer and TNF- $\alpha$ in PBMCs stimulated with LPS. (B) mRNA levels of Dicer and TNF- $\alpha$ in PBMCssupplemented with $10 \%$ serum of patients with rheumatoid arthritis. PBMCs, peripheral blood mononuclear cells; TNF- $\alpha$, tumor necrosis factor- $\alpha$; LPS, lipopolysaccharide.

deficiency in osteoclasts suppresses osteoclastic bone resorption (30). A previous study showed that Anti-Su autoantibodies from patients with RA and systemic lupus erythematosusrecognize the Ago2 and Dicer proteins (31). However, the components of the RNAi machinery in RA remain to be fully elucidated.

In the present study, the mRNA levels of Dicer, Ago2 and Drosha were examined, and the association between their expression levels and specific clinical features of RA were investigated. It was found that the mRNA expression levels of Dicer and Drosha were upregulated in patients with RA, compared with healthy controls, and the mRNA expression of Dicer was correlated with the activity of disease. These results demonstrated that Dicer mRNA can be used as a marker of RA disease activity.

TNF- $\alpha$ is a multifunctional cytokine involved in important biological processes, including cell survival, differentiation, proliferation and death (32). It is also crucial in the pathogenesis of RA. Anti-TNF therapy has shown to benefit patients with RA. To evaluate the effect of the manipulation Dicer on the expression of TNF- $\alpha$, the present study performed in vitro experiments to determine whether Dicer RNAi alters the expression of TNF- $\alpha$. As shown in Fig. 4A, transfection of the cells with Dicer siRNA increased the expression of TNF- $\alpha$. The miR-98 mimic, which downregulated the expression of Dicer, increased the protein expression levels of TNF- $\alpha$, whereas the miR-98 inhibitor, which upregulated the expression of Dicer, decreased the expression of TNF- $\alpha$ (Fig. 4B). These results suggested that the expression of TNF- $\alpha$, was regulated by the manipulation of Dicer. A previous study showed that the nuclear factor $(\mathrm{NF})-\kappa \mathrm{B}$-dependent transcription of Dicer is important for TNF- $\alpha$ homeostasis in hepatocytes. The expression of Dicer and TNF- $\alpha$ were induced in response to the activation of 
$\mathrm{NF}-\kappa \mathrm{B}(33)$. The present study showed that the mRNA levels of Dicer and TNF- $\alpha$ were enhanced following LPS treatment orsupplementation with $10 \%$ serum from patients with RA. Dicer and TNF- $\alpha$ were activated in the serum of patients with RA. In addition, activation of Dicer inhibited the production of TNF- $\alpha$. The outcome of these regulatory mechanisms was the balanced production of TNF- $\alpha$ in RA.

In conclusion, the present study demonstrated that the mRNA expression levels of Dicer and Drosha were upregulated in RA, and that the increased level of Dicer was correlated with disease activityin patients with RA. Therefore, Dicer can be used as a marker of RA disease activity. Dicer and TNF- $\alpha$ were also activated in the serum of patients with RA. The activation of Dicer suppressed the production of TNF- $\alpha$ in RA, and the outcome of these regulatory mechanisms was the balanced production of TNF- $\alpha$ in RA.

\section{Acknowledgements}

This study was supported by a grantfrom the Natural Science Foundation of Shandong Province (grant no. ZR2013HQ044).

\section{References}

1. Fire A, Xu S, Montgomery MK, Kostas SA, Driver SE and Mello CC: Potent and specific genetic interference by double-stranded RNA in Caenorhabditis elegans. Nature 391: 806-811, 1998.

2. Hannon GJ: RNA interference. Nature 418: 244-251, 2002.

3. Lee Y, Ahn C, Han J, Choi H, Kim J, Yim J, Lee J, Provost P, Rådmark O, Kim S and Kim VN: The nuclear RNase III Drosha initiates microRNA processing. Nature 425: 415-419, 2003.

4. Bernstein E, Caudy AA, Hammond SM and Hannon GJ: Role for a bidentate ribonuclease in the initiation step of RNA interference. Nature 409: 363-366, 2001.

5. Sevignani C, Calin GA, Siracusa LD and Croce CM: Mammalian microRNAs: A small world for fine-tuning gene expression. Mamm Genome 17: 189-202, 2006.

6. McManus MT and Sharp PA: Gene silencing in mammals by small interfering RNAs. Nat Rev Genet 3: 737-747, 2002.

7. Meister G, Landthaler M, Patkaniowska A, Dorsett Y, Teng G and Tuschl T: Human Argonaute 2 mediates RNA cleavage targeted by miRNAs and siRNAs. Mol Cell 15: 185-197, 2004.

8. Halder J, Kamat AA, Landen CN Jr, Han LY, Lutgendorf SK, Lin YG, Merritt WM, Jennings NB, Chavez-Reyes A, Coleman RL, et al: Focal adhesion kinase targeting using in vivo short interfering RNA delivery in neutral liposomes for ovarian carcinoma therapy. Clin Cancer Res 12: 4916-4924, 2006.

9. Landen CN Jr, Chavez-Reyes A, Bucana C, Schmandt R, Deavers MT, Lopez-Berestein G and Sood AK: Therapeutic EphA2 gene targeting in vivo using neutral liposomal small interfering RNA delivery. Cancer Res 65: 6910-6918, 2005.

10. McInnes IB and Schett G: The pathogenesis of rheumatoid arthritis. N Engl J Med 365: 2205-2219, 2011.

11. Huang RY, Huang QC and Burgering BM: Novel insight into the role of $\alpha$-actinin-1 in rheumatoid arthritis. Discov Med 17: 75-80, 2014.

12. Salemi S, Biondo MI, Fiorentino C, Argento G, Paolantonio M, Di Murro C, Malagnino VA, Canzoni M, Diamanti AP and D'Amelio R: Could early rheumatoid arthritis resolve after periodontitis treatment only? Case report and review of the literature. Medicine (Baltimore) 93: e195, 2014.

13. Ursini F, Russo E, Letizia Hribal M, Mauro D, Savarino F, Bruno C, Tripolino C, Rubino M, Naty S and Grembiale RD: Abatacept improves whole-body insulin sensitivity in rheumatoid arthritis: An observational study. Medicine (Baltimore) 94: e888, 2015.
14. Miao CG, Yang YY, He X, Xu T, Huang C, Huang Y, Zhang L, Lv XW, Jin Y and Li J: New advances of microRNAs in the pathogenesis of rheumatoid arthritis, with a focus on the crosstalk between DNA methylation and the microRNA machinery. Cell Signal 25: 1118-1125, 2013.

15. Xu T, Huang C, Chen Z and Li J: MicroRNA-323-3p: A new biomarker and potential therapeutic target for rheumatoid arthritis. Rheumatol Int 34: 721-722, 2014.

16. Murata K, Furu M, Yoshitomi H, Ishikawa M, Shibuya H, Hashimoto M, Imura Y, Fujii T, Ito H, Mimori T and Matsuda S: Comprehensive microRNA analysis identifies miR-24 and miR-125a-5p as plasma biomarkers for rheumatoid arthritis. PLoS One 8: e69118, 2013.

17. Abou-Zeid A, Saad M and Soliman E: MicroRNA 146a expression in rheumatoid arthritis: Association with tumor necrosis factor-alpha and disease activity. Genet Test Mol Biomarkers 15: 807-812, 2011.

18. Philippe L, Alsaleh G, Suffert G, Meyer A, Georgel P, Sibilia J, Wachsmann D and Pfeffer S: TLR2 expression is regulated by microRNA miR-19 in rheumatoid fibroblast-like synoviocytes. J Immunol 188: 454-461, 2012.

19. Nagata Y, Nakasa T, Mochizuki Y, Ishikawa M, Miyaki S, Shibuya H, Yamasaki K, Adachi N, Asahara H and Ochi M: Induction of apoptosis in the synovium of mice with autoantibody-mediated arthritis by the intraarticular injection of double-stranded MicroRNA-15a. Arthritis Rheum 60: 2677-2683, 2009.

20. Nakasa T, Nagata Y, Yamasaki K and Ochi M: A mini-review: MicroRNA in arthritis. Physiol Genomics 43: 566-570, 2011.

21. Livak KJ and Schmittgen TD: Analysis of relative gene expression data using real-time quantitative PCR and the 2(-Delta Delta C(T)) Method. Methods 25: 402-408, 2001.

22. Feldmann M: Translating molecular insights in autoimmunity into effective therapy. Annu Rev Immunol 27: 1-27, 2009.

23. Tokumaru S, Suzuki M, Yamada H, Nagino M and Takahashi T: let-7 regulates Dicer expression and constitutes a negative feedback loop. Carcinogenesis 29: 2073-2077, 2008.

24. Lin WJ and Yeh WC: Implication of Toll-like receptor and tumor necrosis factor alpha signaling in septic shock. Shock 24: 206-209, 2005.

25. Waterhouse PM, Wang MB and Lough T: Gene silencing as an adaptive defence against viruses. Nature 411: 834-842, 2001.

26. Meister G and Tuschl T: Mechanisms of gene silencing by double-stranded RNA. Nature 431: 343-349, 2004.

27. Triboulet R, Mari B, Lin YL, Chable-Bessia C, Bennasser Y, Lebrigand K, Cardinaud B, Maurin T, Barbry P, Baillat V, et al: Suppression of microRNA-silencing pathway by HIV-1 during virus replication. Science 315: 1579-1582, 2007.

28. Matskevich AA and Moelling K: Dicer is involved in protection against influenza A virus infection. J Gen Virol 88: 2627-2635, 2007.

29. Kobayashi T, Lu J, Cobb BS, Rodda SJ, McMahon AP, Schipani E, Merkenschlager M and Kronenberg HM: Dicer-dependent pathways regulate chondrocyte proliferation and differentiation. Proc Natl Acad Sci USA 105: 1949-1954, 2008.

30. Mizoguchi F, Izu Y, Hayata T, Hemmi H, Nakashima K, Nakamura T, Kato S, Miyasaka N, Ezura Y and Noda M: Osteoclast-specific Dicer gene deficiency suppresses osteoclastic bone resorption. J Cell Biochem 109: 866-575, 2010.

31. Jakymiw A, Ikeda K, Fritzler MJ, Reeves WH, Satoh M and Chan EK: Autoimmune targeting of key components of RNA interference. Arthritis Res Ther 8: R87, 2006.

32. Chen G and Goeddel DV: TNF-R1 signaling: A beautiful pathway. Science 296: 1634-1655, 2002.

33. Guan Y, Yao H, Wang J, Sun K, Cao L and Wang Y: NF- $\kappa$ B-DICER-miRs axis regulates TNF- $\alpha$ expression in responses to endotoxin stress. Int J Biol Sci 11: 1257-1268, 2015. 